\title{
CHARACTERIZATION OF OPERATOR CONVEX FUNCTIONS BY CERTAIN OPERATOR INEQUALITIES
}

\author{
Hiroyuki Osaka, Yukihiro Tsurumi And Shuhei WadA
}

Abstract. For $\lambda \in(0,1)$, let $\psi$ be a non-constant, non-negative, continuous function on $(0, \infty)$ and let $\Gamma_{\lambda}(\psi)$ be the set of all non-trivial operator means $\sigma$ such that an inequality

$$
\psi\left(A \nabla_{\lambda} B\right) \leqslant \psi(A) \sigma \psi(B)
$$

holds for all $A, B \in B(H)^{++}$. Then we have:

1. $\psi$ is a decreasing operator convex function if and only if

$$
\Gamma_{\lambda}(\psi)=\left\{\sigma \mid !_{\lambda} \leqslant \sigma \leqslant \nabla_{\lambda}\right\}
$$

2. $\psi$ is an operator convex function which is not a decreasing function if and only if

$$
\Gamma_{\lambda}(\psi)=\left\{\nabla_{\lambda}\right\}
$$

The first result is a weighted version of Ando and Hiai's characterization of an operator monotone decreasing function and these two results imply each other.

Mathematics subject classification (2010): 47A64, 47A63.

Keywords and phrases: Operator means, operator monotone functions, operator convex functions.

\section{REFERENCES}

[1] T. Ando And F. Hiai, Operator log-convex functions and operator means, Math. Ann. 350 (2011), $611-630$

[2] J. I. FuJII, Operator means and Range inclusion, Linear Algebra Appl. 170 (1992), 137-146.

[3] F. Hansen And G. K. Pedersen, Jensen's inequality for operator and Löwner's theorem, Math. Ann. 258 (1982) 229-241.

[4] F. HiAI, Matrix analysis: matrix monotone functions, matrix means, and Majorization, Interdiscip. Inform. Sci. vol 16 (2010), no. 2, 139-248.

[5] F. HiAi AND D. PETZ, Introduction to matrix analysis and applications, Universitext, Springer, New Delhi, 2014.

[6] R. A. Horn and C. R. Johnson, Topics in Matrix Analysis, Cambridge University Press, 1990.

[7] F. KRAus, Über Konvexe Mathtrixfunctiouen, Math. Z. 41 (1936) 18-42.

[8] F. Kubo And T. Ando, Means of positive linear operators, Math. Ann. 246 (1980) 205-224.

[9] K. LöWNER, Über monotone matrixfunktionen, Math. Z. 38 (1934) 177-216.

[10] C. P. Niculescu And L.-E. Persson, Convex functions and their applications. A contemporary approach, CMS Books in Mathematics vol. 23, Springer, New York, 2006.

[11] H. Os AKA AND J. TomiYAma, Double piling structure of matrix monotone functions and of matrix convex functions, Linear Algebra Appl. 431 (2009) 1825-1832. 